African Journal for Physical, Health Education,

Recreation and Dance (AJPHERD)

Vol. 12, No. 1 (March) 2006, pp. 50-59.

\section{INFLUENCE OF EXHAUSTION ON METABOLISM AND VISUAL MOTOR PERFORMANCE OF PROFESSIONAL CRICKET PLAYERS}

\author{
P.J. du Toit, P.E. Krüger, K.B. de Wet \\ B. van Vuuren, H.J. van Heerden and \\ C. Janse van Rensburg
}

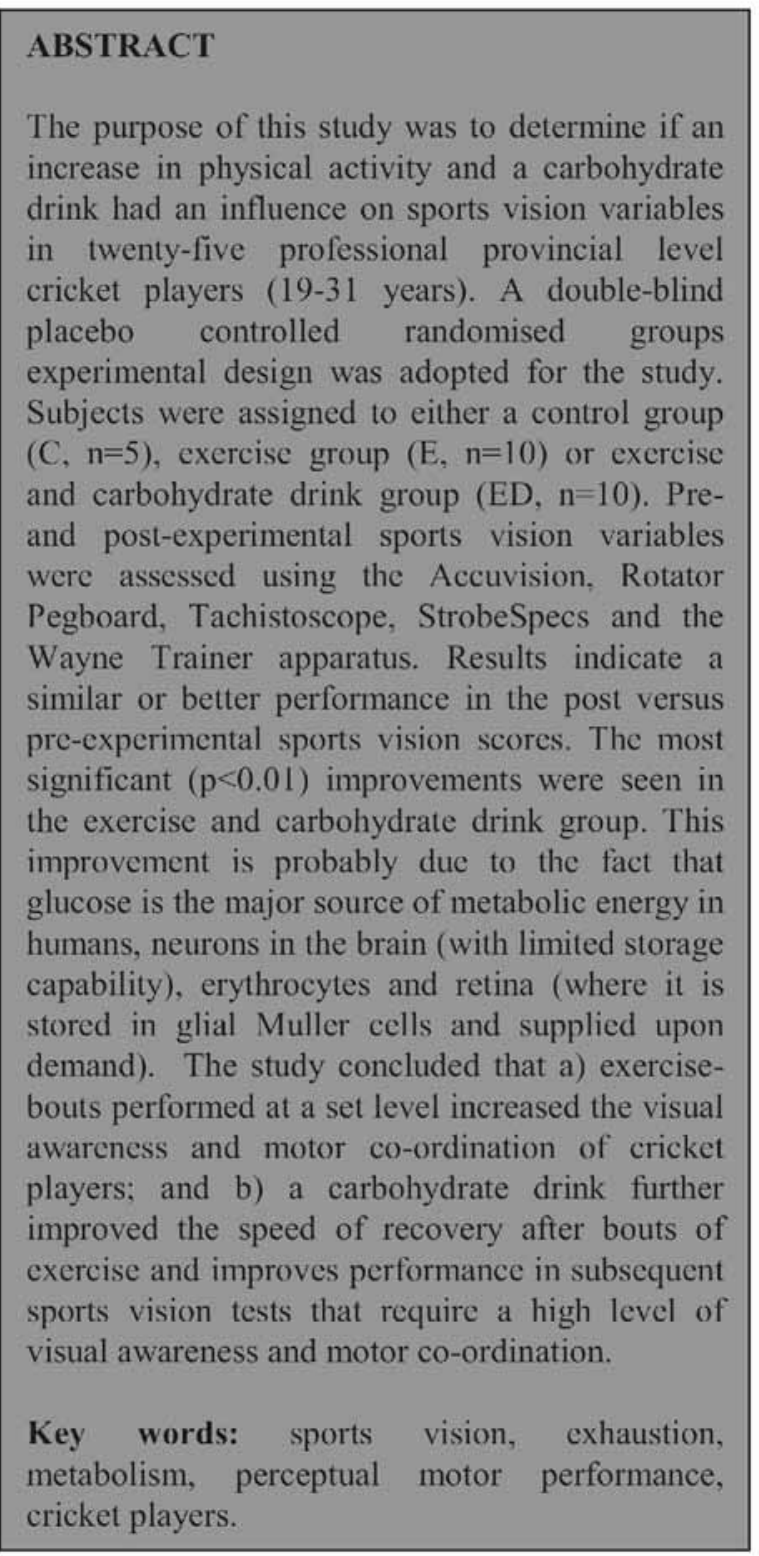

\section{P.J. du Toit}

Department of Physiology

University of Pretoria

\author{
P.E. Krüger, $P h D$ \\ B. van Vuuren \\ H.J. van Heerden \\ Department of Biokinetics \\ Sport and Leisure Sciences \\ University of Pretoria
}

E-mail: kruger@sport.up.ac.za

K.B. de Wet

Department of Sport Sciences

Tshwane University of Technology

Pretoria

\section{Janse van Rensburg}

Section of Sports Medicine

University of Pretoria, South Africa

\section{INTRODUCTION}

In order to measure athletic ability of an individual, it is important to measure the cardiopulmonary and metabolic status of the individual (Weber, 1984; Brown, Wiener \& Brown, 1985; Sue, Chung, Grosvenor \& Wasserman, 1989; Arts \& Kuipers, 1994), but neural aspects like perceptual motor coordination, reaction time, anticipation ability, as well as the real actions required for each type of sport should also be measured to get an indication of an individual's performance ability (Bahill \& La Ritz, 1984). Vision and reaction to visual stimuli in sport is important in contributing to performance enhancement and can be seen as a limiting factor in the differentiation between elite and recreational sports participation (Bahill \& La Ritz, 1984). 
Some sports also require the participant to perform while the visual stimulus is temporarily non-existent and in such cases the ability to predict the event is of utmost importance for example in racquet sports. This prediction of events can be seen in a dual context: on the one hand it can be viewed as an acquired skill, and on the other hand as an intrinsic ability of the visual system. Although distinguishable, both traits have been shown to be interdependent parts of vision as a whole, and are respectively referred to as the 'software' system of learnt skills prediction and also as the 'hardware' system of visual ability (Starkes \& Deakin, 1984; Abernethy \& Russel, 1987; Williams \& Davids, 1992).

Sports Vision as an entity essentially comprises a number of interdependent yet independent definitive variables. Static visual clarity is concerned with the ability of the participant to see objects clearly and accurately, at various distances, while the objects are stationary. Dynamic visual clarity looks at the ability to keep an object in focus while it is in motion (Planer, 1994). Ones ability to track an object regardless of the varying brightness and spectrum colour increases the ability to react to a stimulus more effectively. The rapid identification of objects as they move through space relies on aspects of eye movement, focus flexibility, fusion flexibility and depth perception. These characteristics relate to the ability of the eyes to work together when watching a moving object, to quickly and simultaneously change focus with minimum effort, to fuse these objects together and then to utilise these clear fused images rapidly so as to perceive depth (Planer, 1994).

Visual reaction time is seen as the time from the participant's perception of the stimulus to the moment at which the reaction to that stimulus is performed. In general the shorter the visual reaction time, the better the performance in racquet sports. Eye-hand-body co-ordination and visual adjustment are interdependent of each other. The latter is concerned with the ability of the body to adjust various motor movements rapidly as a reaction to a stimulus, where the stimulus is the ability of the eye to integrate with the body as a unit. 
Central peripheral awareness is concerned with the ability of the individual participant to focus on a central image, while at the same time being aware of any changes of stimulus at the periphery of vision. This enables the participant to react to a wider range of stimuli at once (Planer, 1994). Finally, visualisation is the ability to generate a mental image of a situation before it occurs with regard to action and response, and is vital to many sports. The participant with good visualisation has the luxury of increased time to react to the stimulus before it has occurred. If visualisation is accurate then the skills of visual adjustment and eye-hand-body coordination are improved, as the required response to a stimulus is reduced (Planer, 1994).

Good vision is implicit for performance in a variety of sports requiring the use of a bat and a ball, and none more so than cricket because of the close correlation between the eyes and the bat. In cognisance, the purpose of this study was to test visual parameters among cricket players under three conditions to determine if:

an increase in physical activity would improve the visual response; fatigue plays any role in sports vision performance; and a carbohydrate supplement in conjunction with exercise has an influence on variables of sports vision.

\section{MATERIALS AND METHODS}

A double-blind placebo controlled, pretest-post-test randomised groups experimental design was adopted for the study. Twenty-five professional provincial level cricket players (19-31 years) who provided their informed consent were assigned to either a control group $(\mathrm{C}, \mathrm{n}=5)$, exercise group $(\mathrm{E}, \mathrm{n}=10)$ or exercise and carbohydrate drink group (ED, $\mathrm{n}=10)$.

All subjects followed a standard balanced diet $(70 \%$ carbohydrate, $30 \%$ fat, $15 \%$ protein) for two days prior to the test battery being undertaken to make sure the players' glycogen stores were optimal (Åstrand, Rodahl, Dahl \& Strømme, 2003). The subjects in groups E and ED had their aerobic endurance intensity determined two days prior to the visual testing (de Wet, Du Toit, Van Vuuren, Rossouw \& Steinmann, 1999). 
This was done so that controlled treadmill runs could be performed as exercise bouts between the individual pre- and post sports vision assessments in groups $\mathrm{E}$ and ED. The subjects in group ED also received a commercial carbohydrate drink, in conjunction to the exercise bout, while those in both the exercise only group (E), and the non-exercise control group (C) were given a placebo drink with the same colour and flavour as the carbohydrate drink.

The pre- and post sports vision variables were assessed using five sets of equipment, viz. Accuvision, Rotator Pegboard, Tachistoscope, Strobespecs and the Wayne Trainer (du Toit, Lunsky, Van Vuuren, Van Heerden, Kruger \& Steinmann, 1999) to evaluate combinations of the various visual skills defined in the introduction. The different sets of apparatus were arranged in a certain sequence such that each subject performed a specific sports vision pre-test, followed by the controlled run on the treadmill and the post-test, respectively. After every post-test, the subjects rested for twenty minutes during which time groups $\mathrm{C}$ and $\mathrm{E}$ received the placebo drink and group ED the carbohydrate drink. After the twenty-minute rest period, the subjects proceeded to perform the next sports vision pre-test. The pre-and post intervention values of the subjects within the various groups were pooled and the averages and differences were determined. Inter-group comparisons and significant differences were calculated according to the Kruskal - Wallis test.

\section{Sport Vision Testing Battery}

The Sport Vision Battery utilized consisted of five different hand-eye coordination tests selected to evaluate different parameters of hand-eye coordination. The operational definitions, in conjunction with the procedures, instruments and scoring applied in the tests, were as follows:

\section{Rotator pegboard - Blaupunkt, South Africa}

The rotator pegboard was manufactured by Blaupunkt in South Africa. A wooden disc with 26 holes is placed on a turntable and rotated at $33.3 \mathrm{rpm}$. Each of these 26 holes is numbered with a letter of the alphabet. 
The subject has 3 minutes in which to place a golf tee into each hole. The placing must be done in alphabetical order. The letter reached is recorded, or if $\mathrm{Z}$ is reached within the time limit, the time is recorded. The parameters tested are visual concentration and hand-eye coordination.

\section{Tachistoscope - Rheem Califone Perceptomatic, Portland, USA}

This Tachistoscope was manufactured by Rheem Califone Perceptomatic in Portland, USA. A five-digit number is flashed onto a wall 14 times, using a Rheem Projector. The first 2 numbers are flashed at 1/10 second, the next 4 at 1/25 second, the next 4 at 1/50 second and the last 4 at 1/100 second. The subject writes down each number seen. The scoring is determined as follows: a correct reproduction scores 1 mark and a number only containing 3 or 4 of the correct digits score $1 / 2$ a mark. The parameters tested are visual response (reading) speed, reading accuracy and short term visual memory.

\section{Strobespecs - Maximum Performance, Roseville, California, USA}

This Srobespecs was manufactured by Maximum Performance in Roseville,
California, USA. The subject wears a pair of special purpose glasses with lenses that flash at a given speed allowing the subject limited visual input. A beanbag or tennis ball is thrown from approximately 3 metres either straight at the subject or to his left or right and at various heights. Twenty throws are carried out and the number of successful catches is recorded. The parameter primarily tested is visual anticipation.

\section{The Accuvision 1000-test - Wayne Engineering, Northfield, Illinois, USA}

The Accuvision 1000-testboard was manufactured by Wayne Engineering in Northfield, Illinois, USA. This test is carried out on a display board $(130 \mathrm{~cm}$ in length, $90 \mathrm{~cm}$ in width) with 120 touchsensitive red light emitting diodes (LED's). Digital displays in the top righthand corner of the display board provide a continuous indication of the selected speed and number of correct responses. Two different tests are done. In the first test, 30 lights flash randomly on the Accuvision board and must be touched. As soon as one light is touched, the next one lights up. The subject has to do this as quickly as possible. 
The parameter tested is proaction-reaction time i.e. speed of motor reaction time after sensory input.

The second test consists of 120 lights being flashed at a certain speed (speed 5 on the Accuvision) and a central green fixation light that can randomly switch on and off. If the subject touches the flashing light when the fixation light is off, a negative score is recorded. The score recorded indicates how many lights are touched while the fixation light is on, minus the lights touched while the fixation light is off. The parameters tested are peripheral awareness, proaction-reaction and visual concentration.

In the above tests the first trial is done with the subject balancing on both feet on a wobble board. In the second trial the subject balances on one foot on the wobble board. The wobble board introduces an element of increased proprioceptive concentration, resulting in the visual system to be tested dynamically.

\section{The Wayne Trainer - Wayne Engineering, Northfield, Illinois, USA}

The Wayne Trainer was manufactured by Wayne Engineering, Northfield, Illinois,
USA. Four lights boxes are attached to a computerized control box, which programmes the lights to flash randomly. The boxes are spaced 0.75 metres apart and the subject starts at 2.5 metres from each box. In 30 seconds, the subject must accelerate towards the light flashed, decelerate to touch the light, return to the starting point and repeat the process. In 30 seconds, 15 touches will be the perfect score. The parameter tested is eye-handfoot co-ordination.

\section{Limitations to above tests}

The height of the subject can definitely play an important role. Taller persons will have an advantage in certain tests (e.g. Wayne trainer) due to a longer reach. Therefore, the results were expressed in accordance to the height of the subjects.

\section{Statistical procedures}

Descriptive statistics was used for describing the data. The mean, standard deviation, minimum and maximum scores for each measurement per group were determined for reference purposes. Intergroup comparison and significance were calculated according to the KruskalWallis test (Kruskal-Wallis one-way analysis by ranks) (Tables 1 to 4 ). 
Table 1: Pre-experimental Sports Vision Performance (mean $\pm \mathrm{SD}$ ) of subject-groups.

\begin{tabular}{|l|ccc|}
\hline \multicolumn{1}{|c|}{ Sports Vision Tests } & Control & Exercise & $\begin{array}{c}\text { Exercise \& } \\
\text { Carbohydrate } \\
\text { Drink }\end{array}$ \\
\hline Tachistoscope $(\Delta$ correct reproductions) & $5 \pm 3.3$ & $7.6 \pm 4.2$ & $8.8 \pm 4.3$ \\
StrobeSpecs $\Delta$ successful catches) & $10 \pm 2.3$ & $12.9 \pm 3.8$ & $14.6 \pm 2.9$ \\
Wayne Trainer $(\Delta$ catches) & $11 \pm 3.4$ & $10.8 \pm 2.5$ & $11.1 \pm 3.8$ \\
Accuvision-Test $60(\Delta$ correct responses) & $53.4 \pm 4.4$ & $56.6 \pm 1.3$ & $56 \pm 1.9$ \\
Accuvision-Test 120 $(\Delta$ correct responses) & $68 \pm 8.8$ & $77.4 \pm 5.3$ & $80.9 \pm 4.8$ \\
Rotator Pegboard $(\Delta$ holes in 3 min) & $2.6 \pm 0$ & $2.8 \pm 0.3$ & $2.3 \pm 0.4$ \\
\hline
\end{tabular}

Table 2: Pre-experimental mean Rank Sums (Kruskal - Wallis test) of subject-groups

\begin{tabular}{|l|cccc|}
\hline \multicolumn{1}{|c|}{ Sports Vision Tests } & Control & Exercise & $\begin{array}{c}\text { Exercise+ } \\
\text { Carbo }\end{array}$ & $\begin{array}{c}\text { Significance* of } \\
\text { cross - group } \\
\text { differences }\end{array}$ \\
\hline Tachistoscope $(\Delta$ correct reproductions) & 7.8 & 12.2 & 14.1 & $\mathrm{p}<0.01 *$ \\
StrobeSpecs $(\Delta$ successful catches) & 6.2 & 12.4 & 14.8 & $\mathrm{p}>0.05$ \\
Wayne Trainer $(\Delta$ catches) & 11.6 & 11.7 & 12.5 & $\mathrm{p}>0.05$ \\
Accuvision-Test 60 ( $\Delta$ correct responses) & 8.7 & 13.2 & 12.6 & $\mathrm{p}>0.05$ \\
Accuvision-Test 120 ( $\Delta$ correct responses) & 4.8 & 11.9 & 16.1 & $\mathrm{p}<0.01 *$ \\
Rotator Pegboard $(\Delta$ holes in 3 min) & 13.0 & 15.7 & 7.8 & $\mathrm{p}<0.03 *$ \\
\hline
\end{tabular}

$* \mathrm{p}<0.05$

Table 3: Post-experimental Sports Vision Performance (mean \pm SD) of subject-groups

\begin{tabular}{|l|ccc|}
\hline \multicolumn{1}{|c|}{ Sports Vision Tests } & Control & Exercise & $\begin{array}{c}\text { Exercise \& } \\
\text { Carbohydrate } \\
\text { Drink }\end{array}$ \\
\hline Tachistoscope $(\Delta$ correct reproductions) & $5.9 \pm 2.2$ & $7.7 \pm 4.1$ & $10 \pm 4.4$ \\
StrobeSpecs $(\Delta$ successful catches) & $10.8 \pm 2.3$ & $14.8 \pm 2.5$ & $17 \pm 1.0$ \\
Wayne Trainer $(\Delta$ touches) & $13.2 \pm 2.5$ & $11.2 \pm 3.0$ & $12.7 \pm 3.5$ \\
Accuvision-Test 60 ( $\Delta$ correct responses) & $55.2 \pm 1.8$ & $53.4 \pm 3.3$ & $56.8 \pm 1.9$ \\
Accuvision-Test 120 ( $\Delta$ correct responses) & $72.2 \pm 10.2$ & $79.6 \pm 6.2$ & $83 \pm 4.2$ \\
Rotator Pegboard $(\Delta$ holes in 3 min) & $2.5 \pm 0.2$ & $2.4 \pm 0.1$ & $2.0 \pm 0.4$ \\
\hline
\end{tabular}

Table 4: Post-experimental mean Rank Sums (Kruskal - Wallis test) of subject-groups.

\begin{tabular}{|l|cccc|}
\hline \multicolumn{1}{|c|}{ Sports Vision Tests } & Control & Exercise & $\begin{array}{c}\text { Exercise+ } \\
\text { Carbo }\end{array}$ & $\begin{array}{c}\text { Significance* of } \\
\text { cross - group } \\
\text { differences }\end{array}$ \\
\hline Tachistoscope $(\Delta$ correct reproductions) & 8.8 & 10.7 & 15.0 & $\mathrm{p}<0.01 *$ \\
StrobeSpecs $(\Delta$ successful catches) & 4.0 & 11.3 & 17.2 & $\mathrm{p}<0.0019 *$ \\
Wayne Trainer $(\Delta$ catches) & 14.0 & 9.4 & 13.5 & $\mathrm{p}<0.3$ \\
Accuvision-Test 60 ( $\Delta$ correct responses) & 11.1 & 8.7 & 15.8 & $\mathrm{p}<0.07 *$ \\
Accuvision-Test $120(\Delta$ correct responses) & 6.4 & 11.2 & 15.9 & $\mathrm{p}<0.03 *$ \\
Rotator Pegboard $(\Delta$ holes in 3 min) & 16.5 & 13.0 & 8.5 & $\mathrm{p}<0.08^{*}$ \\
\hline
\end{tabular}

$* \mathrm{p}<0.05$ 


\section{RESULTS AND DISCUSSION}

The pre- and post-intervention sports vision scores of subjects in the control and two experimental groups are reflected in Tables 1-4.

Results indicate a similar or better performance in the post versus preexperimental sports vision scores in the both the $\mathrm{E}$ and ED groups. The most significant $(p<0.01)$ improvements were seen in the ED group, where the level of visual awareness had recovered significantly after twenty minutes rest. These results suggest that the exercise intervention between the pre and post tests heightened the level of visual awareness by improving the vision performance in most tests, and the group that used the carbohydrate drink during the rest period showed signs of improved recovery between the various tests.

Controversies could exist over the effects of an increase in these energetically constraints (cardiac work) on hand-eye coordination. Some results showed a decrement of simple reaction time after an increase in energetically constraints (cardiac work) (Brisswalter, Durand,
Delignieres \& Legros, 1995). Brisswalter et al. (1995) have also shown a linear relationship between $\mathrm{VO}_{2}$ and reaction time performance suggesting that the greater the energetically constraints, the more attention is mobilized to control movements (Brisswalter, Durand, Delignieres \& Legros, 1995).

Other studies provided clear support for an improvement of reaction time performance during exercise (Paas \& Adam, 1991). Factors like an increase of the nervous activation level related to physical exertion (Keen, 1994) and the amount of effort invested in the task as a function of exercise workloads (Delignieres, Brisswalter \& Legros, 1994) may explain the increase in reaction time or decisional performance. Aks (1998) also suggested that exercise improved performance, especially under conditions of focused attention.

The group that used the carbohydrate drink during the rest period (EC group) showed signs of improved recovery between the various tests. 
This improvement is probably due to the fact that glucose is the major source of metabolic energy in humans, neurons in the brain (with limited storage capability), erythrocytes and retina (where it is stored in glial Muller cells and supplied upon demand).

According to Lopez and Sannita (1997), visual function and glucose availability are related. Positron emission tomography studies in humans, indicate increased blood flow and glucose metabolic rate in primary visual cortex during stimulation (Lopez \& Sannita, 1997). Athletes suffering from hypoglycemia show blurred vision and loss control of the external eye muscles which can cause double vision. The eye is very sensitive to the concentration of metabolites, oxygen and blood sugar. A depletion in one of these can have a negative effect on normal vision and thus hand-eye co-ordination, while an increase may have the opposite effect.

\section{CONCLUSION}

The following conclusions are made based on the results of the study:

exercise-bouts performed at a set level will increase the visual awareness and motor co-ordination of cricket players.; and a carbohydrate drink further improves the speed of recovery after bouts of exercise and improves performance in subsequent sports vision tests that require a high level of visual awareness and motor co-ordination.

\section{REFERENCES}

Abernethy, B. \& Russell, D.G. (1987). The relationship between expertise and visual search strategy in a racquet sport. Human Movement Science, 6, 283.

Aks, D.J. (1998). Influence of exercise on visual search: implications for mediating cognitive mechanisms. Perceptual and Motor Skills,87, 771-83.

Arts, F.J.P. \& Kuipers, H. (1994). The relation between power output, oxygen uptake and heart rate in male athletes. International Journal of Sports Medicine, 15, 228.

Åstrand, P-O., Rodahl, K., Dahl, H.A. \& Strømme, S.B. (2003). Textbook of Work Physiology ( $4^{\text {th }}$ edition), Champaign, IL: Human Kinetics.

Bahill, A. \& La Ritz, T. (1984). Why can't batters keep their eyes on the ball? American Scientist, 72, 249.

Brisswalter, J., Durand, M., Delignieres, D. \& Legros, P. (1995). Optimal and non-optimal demand in a dual task of pedalling and simple reaction time: effects on energy expenditure and cognitive performance. Journal of Human Movement Studies, 29, 15-34.

Brown, S.E., Wiener, S. \& Brown, R.A. (1985). Exercise performance following a carbohydrate load in chronic airflow obstruction. Journal of Applied Physiology, 58, 1340.

Delignieres, D., Brisswalter, J. \& Legros, P. (1994). Influence of physical exercise on choice reaction time in sports experts: the mediating role of resource allocation. Journal of Human Movement Studies, 27,173-188. 
De Wet, K., Du Toit, P.J., Van Vuuren, B., Rossouw J. \& Steinmann, C.M.L. (1999). Determining a general aerobic endurance training intensity for cricket players in the off season by using maximal oxygen uptake, heart rate and blood lactate values as parameters. African Journal for Physical, Health Education, Recreation and Dance, 6(2), 190-203.

Du Toit, P.J., Lunsky, J., Van Vuuren, B., Van Heerden, H.J., Kruger, M.C. \& Steinmann, C.M.L. (1999). Hand -eye co-ordination of cricket players after a short period of exercise, African Journal for Physical, Health Education, Recreation and Dance, 5 (2), 160.

Paas, F.G.W. \& Adam, J.J. (1991). Human information processing during physical exercise. Ergonomics, 34, 1385-1397.

Planer, P.M. (1994). Sports Vision Manual. Hamburg: International Academy of Sports Vision.

Lopez, L. \& Sannita, W.G. (1997). Glucose availability and the electrophysiology of the human visual system. Clinical Neuroscience, 4(6), 336340 .

Keen P. (1994). Effect of exercise on simple reaction times of recreational athletes. Perceptual and Motor Skills, 78,123-130.

Starkes, J.L. \& Deakin, J. (1984). Perception in Sport: a cognitive approach to skilled performance. In: W.F. Straub \& J.M. Williams (Eds.), Cognitive Sport Psychology. New York: Sport Science Associates.

Sue, D.Y., Chung, M.M., Grosvenor, M. \& Wasserman, K. (1989). Effect of altering the proportion of dietary fat and carbohydrate on exercise gas exchange in normal subjects. American Reviews in Respiratory Disease, 139, 1430.

Weber, K. (1984). Exercise testing in the evaluation of cardiopulmonary disease. Clinics in Chest Medicine, 5, 175.

Williams, A.M. \& Davids, K. (1992). Perception and action in sport. Journal of Human Movement Studies, 22, 147. 